\title{
DESIGN DUAL UWB RECTANGULAR MICROSTRIP ANTENNA FOR WIRELESS COMMUNICATIONS
}

\section{${ }^{*}$ Masara Nassif Jassim}

1) College of Engineering/ Mustansiriyah Univ. Baghdad-Iraq

2) College of Engineering/ Mustansiriyah Univ. Baghdad-Iraq

\author{
Prof. Dr. Adheed Hasan Sallomi ${ }^{2}$
}

\begin{abstract}
In this paper, we present and proposed design of an innovative and compressed $U$ slot Ultra-wideband (UWB) monopole micro-strip antenna of the size of 19.20 $\mathrm{mm}$ as a length and $28.80 \mathrm{~mm}$ of width. The presented antenna proposed for the wireless applications. The design of the small, thin, and planar UWB antenna includes one $U$ slot radiator which is supplied with one $50 \Omega$ micro-strip line with the reduced ground plane has been excited with the coaxial connector of the SMA. Simulations are performed with the use of the CST Studio Suite software tool. Impedance bandwidth's simulated results have been quite supported with the measurements. The measured group delays and the results of the radiation patterns have been presented as well an analysis/discussion of the antenna efficiency.
\end{abstract}

Keywords: CST,; Ultra-wideband (UWB)

\section{Introduction}

In the past years, the UWB appeared as one of the modern and revolutionary wireless technologies that produced a considerable level of the interest to be used in academia and industry $[1,2]$. The fast progression of the Ultra-wideband as a wireless communication technology of high data rate was fundamentally spurred on with releasing a band-width of $16 \mathrm{GHz}(2.0 \mathrm{GHz}-18.0 \mathrm{GHz})$ for the applications of the Ultra-wideband with FCC (Federal Communications Commission) [3,
4]. Like the case in all the traditional systems of the wireless communications, the antenna plays a highly basic role in the systems of the UWB as well. None-the-less the issues which are encountered in the design of an Ultra-wideband antennas are considerably more. One of the good candidates for the Ultra-wideband applications are the printed monopole antennas because they are compact, lightweight and have simple structures [3-10]. The design antenna has a sharpened U shape slot printed monopole microstrip, which have been stated in the UWB for the wireless applications in the present research. Initially, the design of the planar PCB antennas has been presented.

In addition to that the variety of the dimensions and considerations of the design have been summarized [11]. Ultimately, the measured and simulated results were compared and a new antenna has been explained and produced.

*Corresponding Author: masara.na96@gmail.com 


\section{Ultra-wideband Antenna Design}

The rather small, planar thin Ultra-wideband antenna has been fixed on $19.20 \mathrm{~mm} \times 28.80 \mathrm{~mm}$ FR-4 substrate that has a 4.40 relative permittivity and a $1.60 \mathrm{~mm}$ height of the substrate. The suggested antenna's geometry has been illustrated in figure1, while figure2 represent the antenna ground design. The transmission line and the radiating patch of the $\mathrm{U}$ slot are linked with tapered edges for obtaining more efficient matching of the impedance.

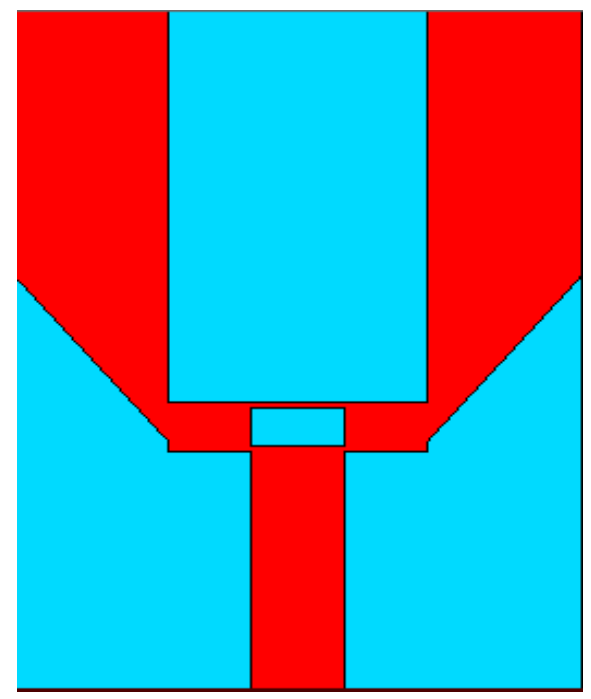

Figure 1. Geometry for the proposed antenna.

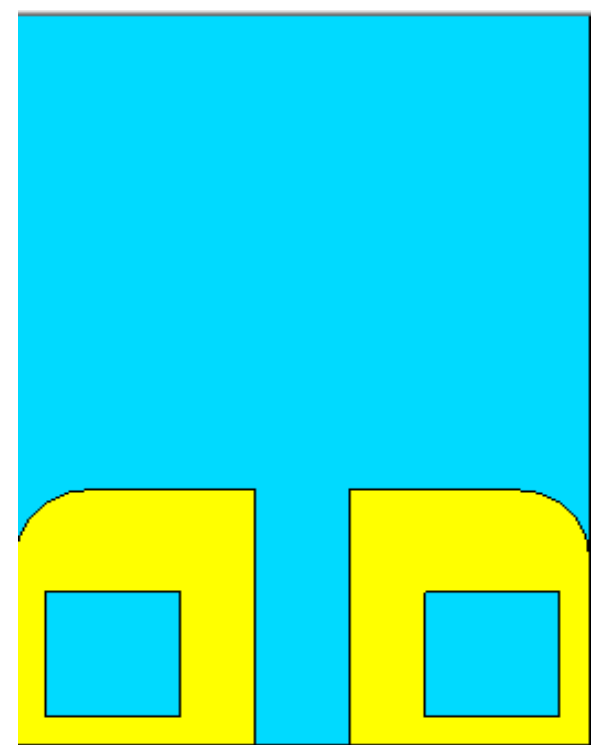

Figure 2. Geometry for the proposed antenna ground.
A part of the ground plane which has a $9.20 \mathrm{~mm}$ length has been utilized on the other substrate's side. It includes a slot of $2.80 \mathrm{mmx} 1.20 \mathrm{~mm}$ dimensions right behind the line of the transmission for improving band-width. The micro-strip patch's resonant length may be acquired through the use of simple effective relative dielectric constants' relations as an operating frequency and substrate parameters function in the following [12].

$$
\begin{aligned}
& \varepsilon_{\text {reff }}=\frac{\varepsilon_{\text {reff }}+1}{2}+\frac{\varepsilon_{\text {reff }}-1}{2}\left[1+12 \frac{h}{W}\right]^{\frac{-1}{2}} \\
& W=\frac{c}{2 f} \sqrt{\frac{2}{\varepsilon_{r}+1}} \\
& L_{e f f}=\frac{c}{2 f \sqrt{\varepsilon_{r e f f}}} \\
& \Delta L=0.5 h \\
& L=L_{\text {eff }}-2 \Delta L
\end{aligned}
$$

The parameter $\mathrm{c}$ equal to the light speed of 2.99 $\times 10^{8}$ in the free space. While the parameter $\mathrm{L}$ denotes the length as well as $\mathrm{W}$ represents the width of resonant patch antennas. Through the simulation of various patches with the parameters of the substrate, there is a possibility in obtaining the suitable values as patch has no ground plane on the other substrate's side as can be seen in figure1. Center frequency which is utilized in simulations $=9 \mathrm{GHz}$. For such substrate parameters and operating frequency that have been discussed earlier, the patch dimensions have been estimated as $\mathrm{L}=11.98 \mathrm{~mm}$ and $\mathrm{W}=15.21 \mathrm{~mm}$. Those dimensions are the start point for the present Ultra-wideband antenna design as can be seen in figurel. The suggested antenna parameters have been provided in the Table1. 
Table 1. UWB antenna parameters.

\begin{tabular}{ccc} 
Serial No. & Symbols & Size $(\mathrm{mm})$ \\
1 & L & 28.8 \\
2 & W & 19.2 \\
3 & L1 & 12.8 \\
4 & L2 & 18.16 \\
5 & L3 & 1.04 \\
6 & L4 & 1.2 \\
7 & L5 & 0.4 \\
8 & L6 & 9.2 \\
9 & W1 & 5.2 \\
10 & W2 & 8.2 \\
11 & W3 & 3.2 \\
\hline
\end{tabular}

Some of the modifications have been proposed on this patch for improving its operating bandwidth. The first modification has been tapering the patch which is near the feeding line of the micro-strip. As a result of tapering impact of that part which is attached to micro-strip line, the patch dimensions have been altered through the simulations for being matched with line, in a way that the patch length is altered into $12.80 \mathrm{~mm}$ and width is altered into $19.20 \mathrm{~mm}$ as has been stated in the table1. The use of those dimension values with the length of the tapering L_taper equal to $6.40 \mathrm{~mm}$ are sufficient for introducing an Ultrawideband antenna operating in a frequency that ranges between $4.10 \mathrm{GHz}$ and $14 \mathrm{GHz}$ as can be seen by simulated results in section below.

\section{Results and Discussion}

Figure 3 illustrates the variants of simulated and measured results of the bandwidth of impedance (VSWR less than 2) for presented Ultrawideband antenna. The measures have been carried out with the use of the vector network analyzer (VNA, PNA N-5230-A, Agilent Tech.). Results have shown that the suggested produced antenna achieved a band-width or impedance (VSWR less than 2) from $2.0 \mathrm{GHz}-18.0 \mathrm{GHz}$. Some of the differences in measured and simulated curves of the return loss that shown in the $\mathrm{S}-11$ plots can be observed. The main reason behind that is the measuring carried out under non-controlled situations.

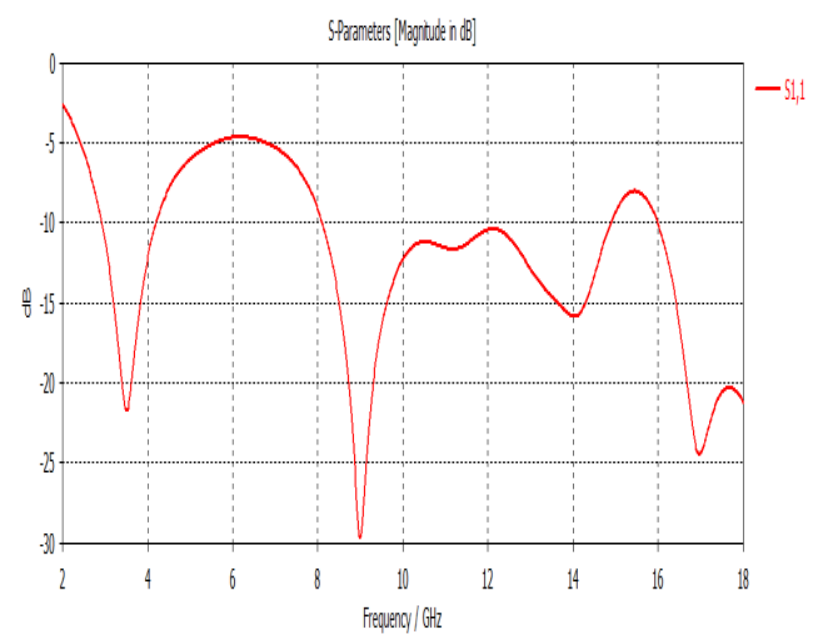

(a)

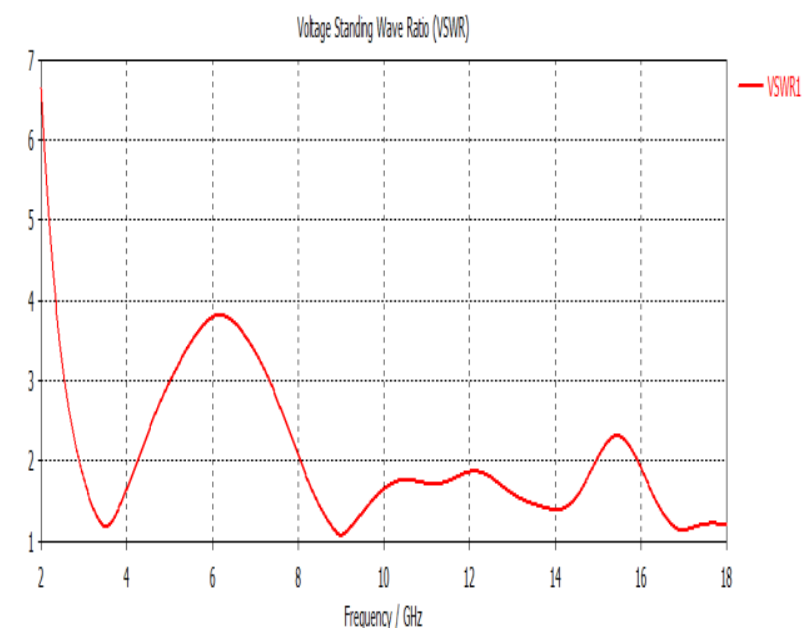

(b)

Figure 3 (a \& b). Simulated of S-11 and VSWR variation. 
Figure 4 shows the patterns of simulated radiation of suggested antenna at $6.50 \mathrm{~Hz}, 4.50 \mathrm{HZ}, 8.50 \mathrm{~Hz}$ and $10.50 \mathrm{GHz}$. The patterns of the far field radiations have been evaluated with the use of the C-band ( $2 \mathrm{GHz}-8 \mathrm{GHz})$ and $\mathrm{X}$-band $(8 \mathrm{GHz}-18.0$ $\mathrm{GHz}$ ) the benches of the Micro-wave at 3.50 $\mathrm{GHz}, 8.99 \mathrm{GHz}$, and $16.976 \mathrm{GHz}$ have been plotted in the Figure5.

Farfield Directivity Abs (Phi=0)

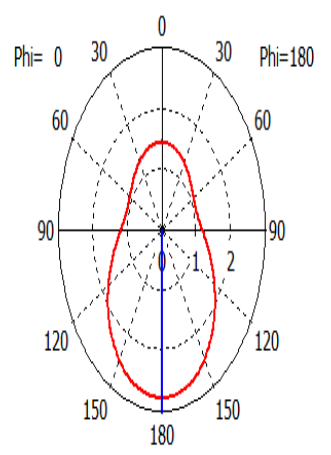

Theta / Degree vs. dBi

(a)

Farfeld Directivity Abs (Phi=0)

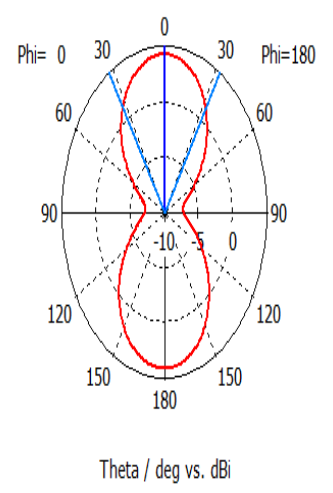

(b)

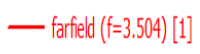

Frequency $=3.504 \mathrm{GHz}$ Main lobe magnitude $=2.76 \mathrm{dBi}$ Main lobe direction $=180.0$ deg.

Frequency $=8.99 \mathrm{GHz}$

Main lobe magnitude $=4.25 \mathrm{dBi}$ Main lobe direction $=0.0$ deg. Angular width $(3 \mathrm{~dB})=64.7 \mathrm{deg}$.

Farfeld Directivity Abs (Phi=0)

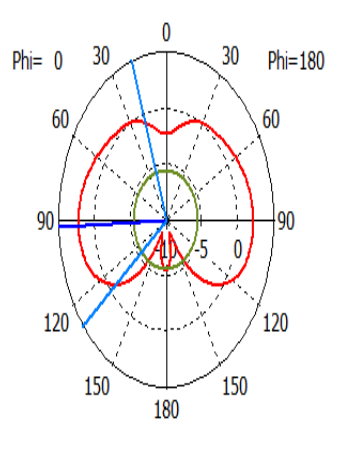

Theta / Degree vs. dBi

(c)

Figure 4 (a, b. and c). Simulated Radiation patterns at $3.5,8.9, \& 16.976 \mathrm{GHz}$ respectively.

It can be clearly observed that the patterns of Eplane radiation have been monopole while the patterns of the $\mathrm{H}$-plane radiation illustrate nearly omni-directional properties, particularly at lower frequency values. None-the-less radiation patterns begin changing in greater frequency values and the Ultra-wideband antenna turns to be directive. The simulated gain of the antenna ranges between $4.40 \mathrm{~dB}$ and $6.0 \mathrm{~dB}$ over operating Ultra-wideband range of frequency as can be seen in Figure 5 (a, b, and c).

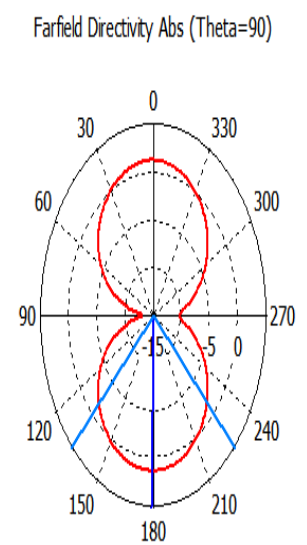

Phi / Degree vs. dBi
— farfield $(f=3.504)[1]$

Frequency $=3.504 \mathrm{GHz}$ Main lobe magnitude $=1.18 \mathrm{dBi}$ Main lobe direction $=179.0$ deg. Angular widh $(3 \mathrm{~dB})=92.2 \mathrm{deg}$.

(a) 


\section{Farfield Directivity Abs (Theta=90)}

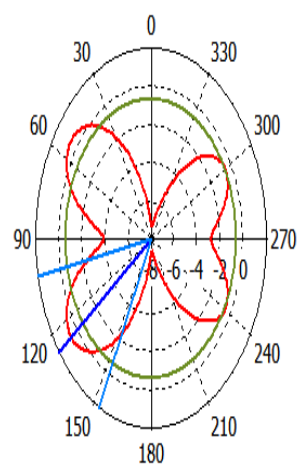

Phi / Degree vs. dBi

(b)

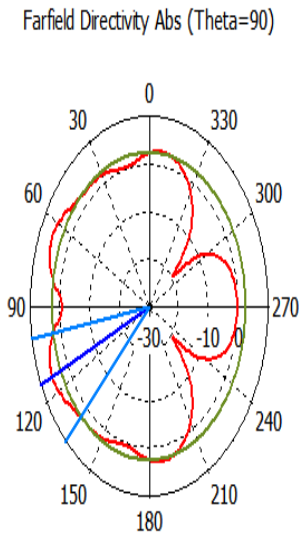

Phi / Degree vs. dBi
— farfield $(f=8.99)[1]$

Frequency $=8.99 \mathrm{GHz}$

Main lobe magnitude $=0.576 \mathrm{dBi}$ Main lobe direction $=127.0 \mathrm{deg}$. Angular width $(3 \mathrm{~dB})=51.9 \mathrm{deg}$. Side lobe level $=-1.2 \mathrm{~dB}$

— farfeld $(f=16.976)[1]$

Frequency $=16.976 \mathrm{GHz}$

Main lobe magnitude $=5.48 \mathrm{dBi}$

Main lobe direction $=114.0$ deg.

Angular width $(3 \mathrm{~dB})=35.7 \mathrm{deg}$

Side lobe level $=-2.8 \mathrm{~dB}$

(c)

Figure 5. Measured Radiation patterns at 3.5, $8.99 \&$ $16.97 \mathrm{GHz}$.

\section{Conclusions}

An innovative small Ultra-wideband antenna was modeled, measured, simulated, and produced. The results of the simulation which have been obtained from the CST Studio Suite software shows to be coinciding with measured results. Group delay that is a more relevant parameter towards showing sufficient properties of the time domain in the Ultra-wideband antennas has been researched and variants which have been

produced are sufficient as well, and in the limit of the acceptable. For miniaturizing the Ultrawideband antennas, the tapering and the truncated ground plains have been utilized. It can be observed from measured results which quite large band-width has been produced for the suggested antenna that may be utilized in the Ultra-wideband systems of communication.

\section{Acknowledgements}

This work is supported by Electrical Department/ Faculty of Engineering/ Mustansiriyah University.

\section{Conflict of interest}

The authors whose listed their names in this paper certify that they have NO affiliations with or involvement in any organization or entity with any financial interest in the subject matter or materials discussed in this manuscript.

\section{References}

1. M. Dye.(2020) "Design of Suction Stabilized Floats for First Responder Localization via Ultra-Wideband (UWB) and Internet of Things (IoT)," Arizona State University, 2020 .

2. S. Elajoumi, A. Tajmouati, J. Zbitou, A. Errkik, A. Sanchez, and M. J. T. Latrach.(2019) "Bandwidth enhancement of compact microstrip rectangular antennas for UWB applications," vol. 17, no. 3, pp. 15591568 .

3. H. J. A. H. Schantz, Inc.(2005) "Ultrawideband antennas."

4. G. R. Aiello and G. D. J. I. m. m. Rogerson.(2003) "Ultra-wideband wireless systems," vol. 4, no. 2, pp. 36-47.

5. E. G. Lim, Z. Wang, C.-U. Lei, Y. Wang, and K. J. I. I. j. o. c. s. Man.(2010) "Ultra wideband antennas: past and present." 
6. R. Khalilpor, J. Nourinia, and C. J. P. P. Ghobadi, Xi'an, China.(2010) "An optimized monopole microstrip patch antenna with gradual steps for ultra wide band applications."

7. H. W. Song, J. K. Park, J. H. J. M. Yoo, and O. T. Letters.(2008) "A novel ultra-wideband monopole antenna with two symmetrical strips," vol. 50, no. 11, pp. 2845-2848.

8. X.-C. Yin, C.-L. Ruan, C.-Y. Ding, and J.-H. J. P. I. E. R. Chu.(2008) "A planar U type monopole antenna for UWB applications," vol. 2, pp. 1-10.

9. Y. Lee, S. Hong, J. Kim, and J. J. E. j. Choi.(2010) "Design of an Internal Antenna with Near-Omnidirectional H-Plane Radiation Pattern over Ultra-wide Bandwidth," vol. 32, no. 1, pp. 62-67.

10. N. Sharma, S. S. J. I. J. o. R. Bhatia, and M. C. A. Engineering.(2019) "Design of printed monopole antenna with band notch characteristics for ultra-wideband applications," vol. 29, no. 10, p. e21894.

11. M. H. Abdullah, A. R. J. J. o. E. P. Othman, and E. Systems.(2019) "Design and Development of UWB Microstrip Patch Antenna Structure at Frequency $5.8 \mathrm{GHz}$ for UWB Indoor Application," vol. 1, no. 1.

12. C. A. Balanis.(2016) Antenna theory: analysis and design. John wiley \& sons, 2016. 